\author{
Nadira A Hatim \\ BDS, MSc (Assist Prof) \\ Ayad A Abdul-Razaq \\ BSC,MSc, PhD (Assist Prof) \\ Ibtehal H Al-Zubaidy \\ BDS, MSc (Assist Lect)
}

\section{Finite Element Analysis of Acrylic Den- ture Produced from Metal Stock Tray}

\author{
Department of Prosthetic Dentistry \\ College of Dentistry, University of Mosul \\ Department of Civil engineering \\ College of Engineering, University of Mosul \\ Department of Prosthetic Dentistry \\ College of Dentistry, University of Mosul
}

\begin{abstract}
Aims: To determine stress analysis exerted by denture on the edentulous alveolar bone in the premolar region represented by stone cast produced from metal stock tray using linear finite element method. Materials and methods: Metal perforated stock tray was used to produce stone cast that represent the denture base and the underlying bone using silicone impression material. The dimension of the cross section of the stone cast was measured using Dimax program, then the data collected was entering Excel program for making the figures. The dimension of the cross section of the stone cast entering finite element program and other new auxiliary program prepared specially for this study for finite element analysis. Results: After the data was analyzed, the results were drawn in figures using surfer 7 program. High compressive, tensile, deflection, shear and maximum principal stress values were observed below the point of force application and in the underlying structure with different values and locations according to the analysis in the mucous membrane and in the underlying bone in the $\mathrm{X}$ and $\mathrm{Y}$ axes. Conclusions: By using finite element analysis, the more stress concentration and deflection were found below the point of force application, in the mucous membrane, at the beginning of the cortical bone and along the buccal vestibule.

Key Words: Finite element, Alveolar bone, Stock tray.
\end{abstract}

Hatim NA, Abdul-Razaq AA, Al-Zubaidy IH. Finite Element Analysis of Acrylic DentureProduced from Metal Stock Tray. Al-Rafidain Dent J. 2009; 9(1):1-8.

Received: 4/9/2007

Sent to Referees: $4 / 9 / 2007$

Accepted for Publication: :25/11/2007

\section{INTRODUCTION}

The material of custom trays should have better dimensional stability and more accuracy to obtain the denture base with less dimensional changes and better stress distribution on the edentulous residual ridge ${ }^{(1,2)}$. Finite element method is a powerful research tool used to examine complex mechanical behavior of prosthesis and surrounding structures that are other wise difficult to assess. It divides the structure into discrete elements, the elements are connected at points called nodes, also, elements have the same properties of the structure ${ }^{(3)}$.
Kawasaki et al. ${ }^{(4)}$ stated that for a complete denture to function effectively, the denture must be stabilized during mastication. They found that maximum stresses were distributed on the alveolar ridge in which the resorption is sever and the distal load produced large compressive stresses on the inclined plane of posterior alveolar ridge.

Uto (5) stated that the motions and stress distributions of mandibular complete dentures during use were compared and investigated in terms of denture rigidity using three dimensional finite element method stress analysis. 
The purpose of this study was to determine stress analysis exerted by denture on the edentulous mandibular alveolar bone in the premolar region represented by stone cast produced from metal stock tray using linear finite element method.

\section{MATERIALS AND METHODS}

Metal perforated stock tray was selected and corrected to fit accurately on the master model, which is completely edentulous mandibular metal arch form, metal perforated stock tray was used to take impression using silicone impression material to produce stone cast.

For the finite element method, the stone cast produced from metal perforated stock tray that represent the denture base and the underlying bone was section in the horizontal direction in the premolar region by using fine saw, the dimension of the cross section of stone cast was measured by using Dimax program. A stand held digital camera was placed $(60 \mathrm{~cm})$ away from the dental surveyor in zero plane that contain the cross section of stone cast produced from metal perforated stock tray, then the picture analyzed by entering Dimax program, a ruler was used to detect the accuracy of the measurements, the measurements were done each $(2 \mathrm{~mm})$ in two dimension.

Cross Section Dimension:*Tooth and denture base:The tooth model was designed according to the average anatomic dimensions of selected set of teeth that were used for previous arrangement, (Cervico - incisal crown length $8 \mathrm{~mm}$, Mesio distal crown diameter $7 \mathrm{~mm}$ ), the denture base thickness $2.5 \mathrm{~mm}^{(6)}$.

*Mucous membrane and bone: The mucous - membrane thickness $2 \mathrm{~mm}^{(7)}$, the cortical bone $2 \mathrm{~mm}$ thickness ${ }^{(8)}$, the bone height was $22.5 \mathrm{~mm}$ according to the master model used.

Materials Properties: The proper value of the modulus of elasticity "E" and Poisson's ratio " $v$ "are shown in Table (1).Mesh Generation: A fine mesh of the finite element model generated using the 8 - node isoparametric element as shown in Figure (1). The 8 - node elements having two degree of freedom at each node, define the translation in the nodal $\mathrm{X}$ and $\mathrm{Y}$ directions at each node. The mesh for the model produced from metal stock tray consists of (916) elements and (2891) nodes.

Finite Element Method: The finite element method is a general method of structural analysis in which a continuum is replaced by finite number of element interconnected at finite number of nodal points.

Shape Function: Eight - node element considered from high order - elements, in general, higher order element shape function can be developed by adding additional nodes to the sides of the linear element.

In this study, the cross section of the model is represented by 8 - nodes isoparametric plane strain element using standard shape function with two degrees of freedom at each node. Formulation of this element is formed by natural coordinate system $(\xi, \eta)$ in place of cartesian coordinates Figure (2).

The nodal displacement vectors for these elements are:

$$
\{\mathrm{d}\}=\left[\mathrm{u}_{1}, \mathrm{v}_{1}, \mathrm{u}_{2}, \mathrm{v}_{2}, \ldots ., \mathrm{u}_{8}, \mathrm{v}_{8}\right]^{\mathrm{T}}
$$

Where $\mathrm{u}$ and $\mathrm{v}$ are the translation in the $\mathrm{X}$ and $\mathrm{Y}$ directions respectively. The displacement field for two - dimensional element is given by:

$$
\begin{aligned}
& \left\{\begin{array}{l}
u \\
v
\end{array}\right\}=[N]\left\{\begin{array}{l}
u_{1} \\
v_{1} \\
\cdot \\
\cdot \\
u_{8} \\
v_{8}
\end{array}\right\} \ldots(2) \text { Where } \\
& {[N]=\left[\begin{array}{ccccccc}
N_{1} & 0 & N_{2} & 0 & \ldots . . & N_{8} & 0 \\
0 & N_{1} & 0 & N_{2} & \ldots . . & 0 & N_{8}
\end{array}\right]}
\end{aligned}
$$$$
\text { ...(3) Where: } \mathrm{N}_{\mathrm{i}} \text { is the shape func- }
$$

tion and, 


$$
\begin{aligned}
& N_{1}=-\frac{1}{4}(1-\xi)(1-\eta)(1+\xi+\eta) \\
& N_{2}=\frac{1}{2}\left(1-\xi^{2}\right)(1-\eta) \\
& N_{3}=\frac{1}{4}(1+\xi)(1-\eta)(\xi-\eta-1) \\
& N_{4}=\frac{1}{2}(1+\xi)\left(1-\eta^{2}\right) \\
& \mathrm{N}_{5}=\frac{1}{4}(1+\xi)(1+\eta)(\xi+\eta+1) \\
& \mathrm{N}_{6}=\frac{1}{4}\left(1-\xi^{2}\right)(1+\eta) \\
& \mathrm{N}_{7}=\frac{1}{4}(1-\xi)(1+\eta)(-\xi+\eta+1) \\
& \mathrm{N}_{8}=\frac{1}{2}(1-\xi)\left(1-\eta^{2}\right)
\end{aligned}
$$

The global coordinates $\mathrm{X}$ and $\mathrm{Y}$ inside the element can be described as:

$$
X=\sum_{i=1}^{8} N_{i} X_{i} \quad \text { and } \quad Y=\sum_{i=1}^{8} N_{i} Y_{i}
$$

Where $\left(\mathrm{X}_{\mathrm{i}}\right)$ and $\left(\mathrm{Y}_{\mathrm{i}}\right)$ represent the coordinates of two - dimensional nodes.

Strain Matrix: Strain component can be calculated from the following expression:

$$
\begin{aligned}
& \{\varepsilon\}=[B][d] \\
& \{\varepsilon\}=\sum_{i=1}^{8}\left[\begin{array}{ll}
\frac{\partial N_{i}}{\partial x} & 0 \\
0 & \frac{\partial N_{i}}{\partial y} \\
\frac{\partial N_{i}}{\partial y} & \frac{\partial N_{i}}{\partial x}
\end{array}\right]\left\{\begin{array}{l}
u_{i} \\
v_{i}
\end{array}\right\} \ldots \ldots . .(7)
\end{aligned}
$$

Consider for instance the set of local coordinate $(\xi, \eta)$ and corresponding set of global coordinates $\mathrm{X}, \mathrm{Y}$ by the usual rule of partial differentiation, the derivative can be written as:

$$
\begin{aligned}
& \frac{\partial N_{i}}{\partial \xi}=\frac{\partial N_{i}}{\partial x} \frac{\partial x}{\partial \xi}+\frac{\partial N_{i}}{\partial y} \frac{\partial y}{\partial \xi} \\
& \frac{\partial N_{i}}{\partial \eta}=\frac{\partial N_{i}}{\partial x} \frac{\partial x}{\partial \eta}+\frac{\partial N_{i}}{\partial y} \frac{\partial y}{\partial \eta}
\end{aligned}
$$
ing in matrix from:

$$
\left\{\begin{array}{c}
\frac{\partial \mathrm{N}_{\mathrm{i}}}{\partial \xi} \\
\frac{\partial \mathrm{N}_{\mathrm{i}}}{\partial \eta}
\end{array}\right\}=\left[\begin{array}{ll}
\frac{\partial \mathrm{x}}{\partial \xi} & \frac{\partial \mathrm{y}}{\partial \xi} \\
\frac{\partial \mathrm{x}}{\partial \eta} & \frac{\partial \mathrm{y}}{\partial \eta}
\end{array}\right]\left\{\begin{array}{c}
\frac{\partial \mathrm{N}_{\mathrm{i}}}{\partial \mathrm{x}} \\
\frac{\partial \mathrm{N}_{\mathrm{i}}}{\partial \mathrm{y}}
\end{array}\right\}=[\mathrm{J}]\left\{\begin{array}{c}
\frac{\partial \mathrm{N}_{\mathrm{i}}}{\partial \mathrm{x}} \\
\frac{\partial \mathrm{N}_{\mathrm{i}}}{\partial \mathrm{y}}
\end{array}\right\}(
$$

9)where:

$$
[J]=\left[\begin{array}{cc}
\sum_{i=1}^{8} \frac{\partial N_{i}}{\partial \xi} X_{i} & \sum_{i=1}^{8} \frac{\partial N_{i}}{\partial \xi} Y_{i} \\
\sum_{i=1}^{8} \frac{\partial N_{i}}{\partial \eta} X_{i} & \sum_{i=1}^{8} \frac{\partial N_{i}}{\partial \eta} Y_{i}
\end{array}\right]
$$

The matrix $[\mathrm{J}]$ is known as Jacobian matrix. To find the global derivative, we invert [J] and write: $\left\{\begin{array}{c}\frac{\partial N_{i}}{\partial x} \\ \frac{\partial N_{i}}{\partial y}\end{array}\right\}=[J]^{-1}\left\{\begin{array}{c}\frac{\partial N_{i}}{\partial \xi} \\ \frac{\partial N_{i}}{\partial \eta}\end{array}\right\}$

To transform the variables, derivatives, and the regions with respect to which integration is made a standard process will be used which involve the determinant of [J], thus the volume of the element: $\mathrm{dx} d \mathrm{y}=|\mathrm{J}| \cdot \mathrm{d} \xi \mathrm{d} \eta$

Elasticity Matrix (D - Matrix): The stress/ strain relationship for an elastic material, in the absence of initial stresses and strains, may be written in the form:

$$
\{\sigma\}=[\mathrm{D}]\{\varepsilon\}
$$

$[\mathrm{D}]$ is the elasticity matrix.

For plane strain situations the D matrix will be:

$$
[D]=\frac{E(1-v)}{(1+v)(1-2 v)}\left[\begin{array}{ccc}
1 & \frac{v}{1-v} & 0 \\
\frac{v}{1-v} & 1 & 0 \\
0 & 0 & \frac{1-2 v}{2(1-v)}
\end{array}\right]
$$

For two-dimensional analysis the stiffness matrix is: $[\mathrm{k}]=\iint[\mathrm{B}]^{\mathrm{T}}[\mathrm{D}][\mathrm{B}] \mathrm{dx} d \mathrm{y}$

(15) Where: D: elasticity matrix. B: strain - displacement matrix.

Depending on the volume of the element $\quad d x d y=|J| . d \xi d \eta, \quad$ the stiffness matrix will be: 


$$
[\mathrm{k}]=\int_{-1}^{1} \int_{-1}^{1}[\mathrm{~B}]^{\mathrm{T}}[\mathrm{D}][\mathrm{B}]|\mathrm{J}| \mathrm{d} \xi \mathrm{d} \eta
$$

Algebraic integration usually defines mathematical expression, and numerical integration has to be used by Hinton and Owen, $1977^{(9)}$.

Boundary Conditions: The lower border of the mandible was considered to be fixed in all directions to avoid the FE model

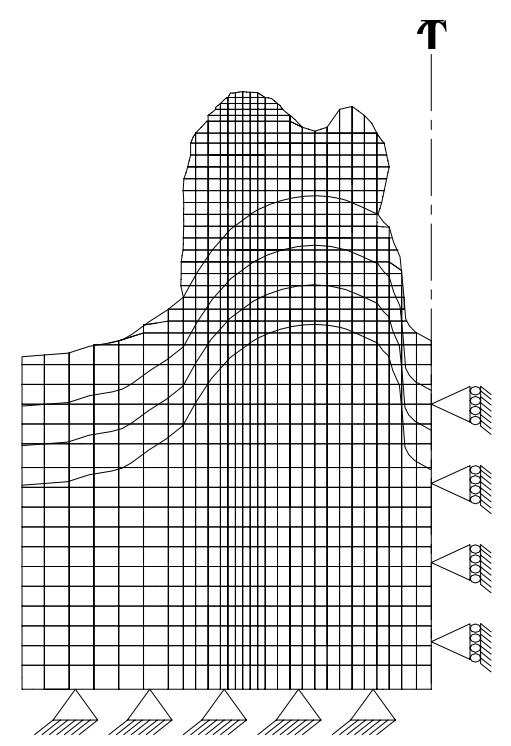

Figure (1): 2-Dimension plane strain mesh in acrylic denture and underlying bone produce from metal stock tray from sinking when load is applied ${ }^{(3)}$.

Load Application: A vertical load of 100 Newton was applied on the buccal cup (supporting cusp) of the second premolar tooth, this value is less than the actual maximum load in the oral cavity during normal mastication, but it is within the measured values in many previous studies in this area of oral cavity ${ }^{(14)}$.

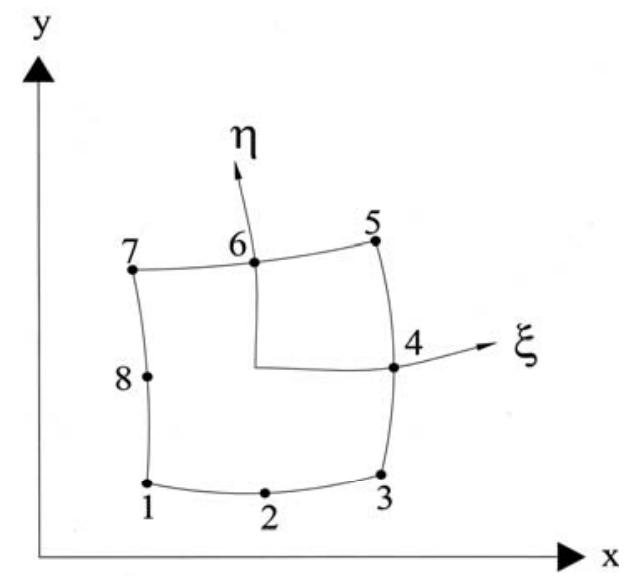

Figure (2) Eight nodes two-dimensional eleelement

Table (1) Properties of materials used in this study

\begin{tabular}{ccc}
\hline Material & Modulus of Elasticity (MPa) & Poisson's ratio \\
\hline Acrylic Resin & 2000 & $0.3^{(10,11,12)}$ \\
Mucosa & 3.45 & $0.45^{(10,11,12)}$ \\
Cortical Bone & 13700 & $0.3^{(13)}$ \\
Cancellous Bone & 1370 & $0.3^{(13)}$ \\
\hline
\end{tabular}

\section{RESULTS}

After the data was analyzed by using FE program and other new auxiliary programs that were prepared specially for this study, the results were drawn in figures using surfer 7 program. The figures are colored to show the stress distribution in the model and these colors are divided every $(20 \mathrm{MPa})$ for stresses and $(0.1 \mathrm{~mm})$ for deflections.

Stresses: High compressive stress values were observed below the point of force application at the buccal cusp of the second bicuspid tooth and in the mucous membrane in the buccal direction which was (-20 to $-120,-40$ to $-200 \mathrm{MPa})$ in the $\mathrm{X}$ and $\mathrm{Y}$ axes respectively in the model that analyzed to the mucous membrane, 
while in the model that analyzed to the underlying bone the high compressive stress values were observed below the point of force application and in the mucous membrane and the underlying bone which was (-20 to $120,-20$ to $-200 \mathrm{MPa})$ in the $\mathrm{X}$ and $\mathrm{Y}$ axes respectively.

The higher tensile stress values were observed in the mucous membrane at the crest of the ridge, and below the lingual cusp of the second bicuspid tooth (0 to 60 $\mathrm{MPa}$ ) in the $\mathrm{X}$ and $\mathrm{Y}$ axes respectively in the model that analyzed to the mucous membrane and (20 to $60 \mathrm{MPa}$ ) in the $\mathrm{X}$ and $\mathrm{Y}$ axes respectively in the model that analyzed to the underlying bone. The contour line of the stress values is shown in Figure (3 A and $\mathrm{B}$ ) and Figure (4 A and B).

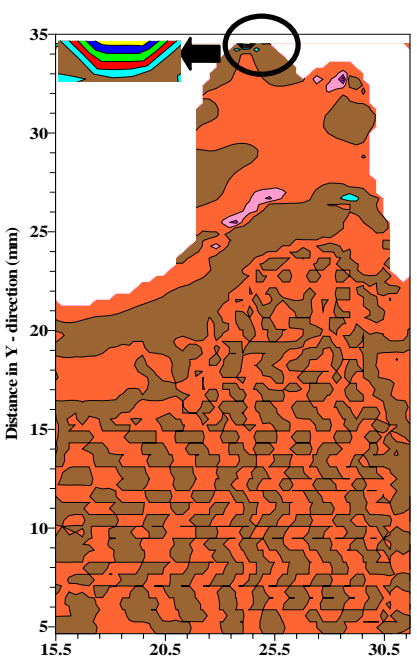

(A)Stress in $\mathrm{X}$ direction(MPa)

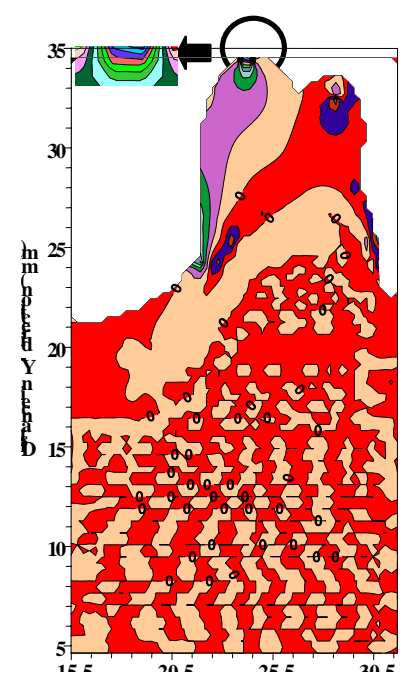

(B)Stress in $\mathrm{X}$ direction( $\mathrm{MPa})$

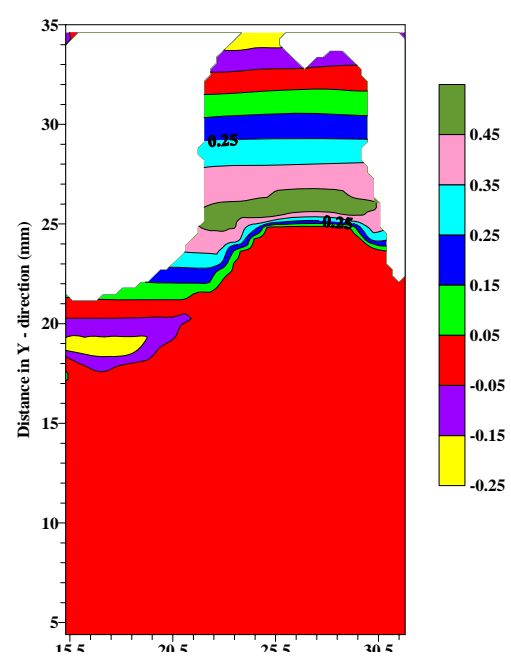

(C)Deflection in X direction( $\mathrm{mm})$

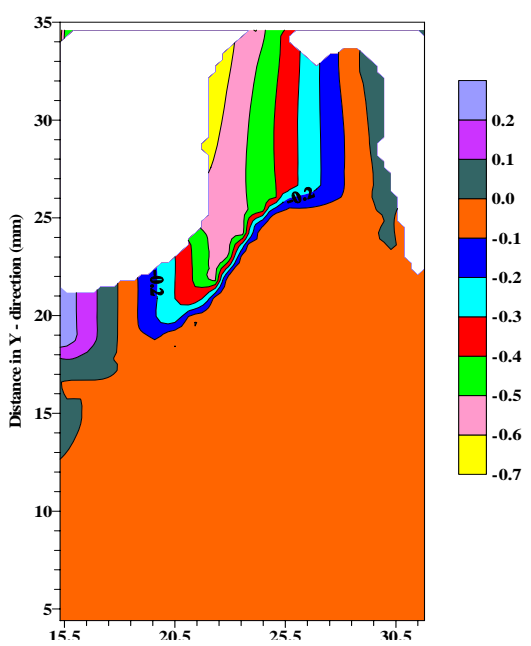

(D) Deflection in Y Direction(mm)
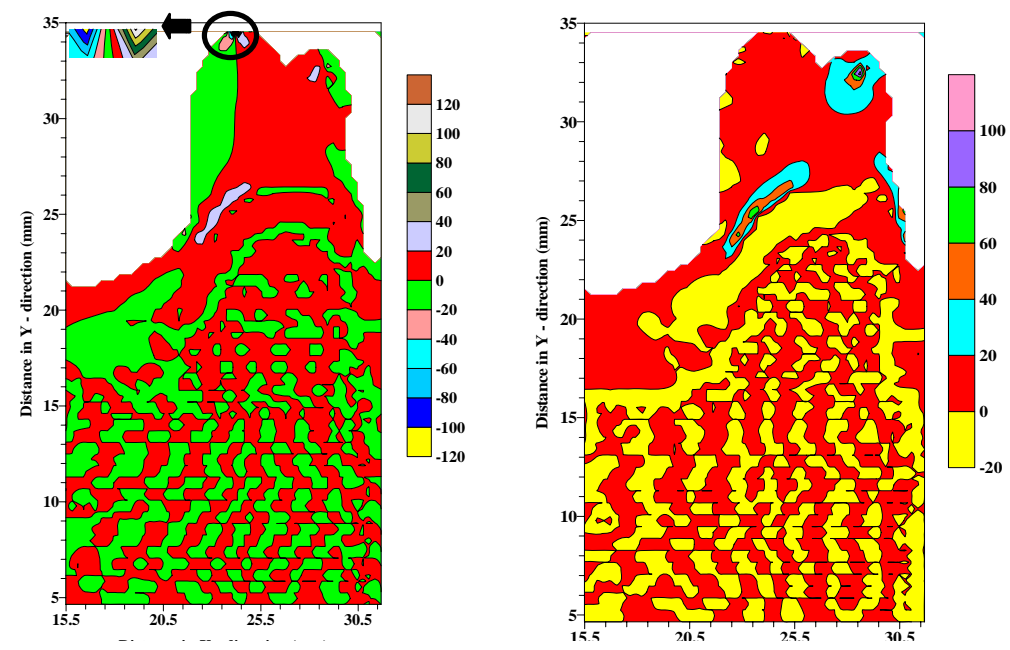

(E)Shear stress(MPa) (F) Maximum principal stress (MPa)

Figure (3): Finite element analysis of acrylic denture to the mucous membrane (metal stock tray) 


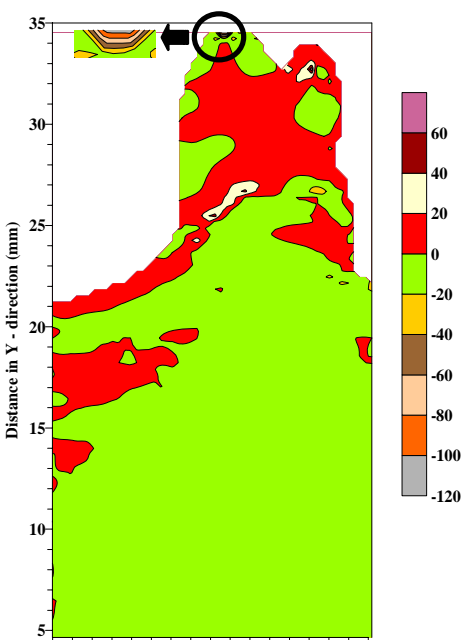

(A)Stress in $\mathrm{X}$ direction( $\mathrm{MPa})$

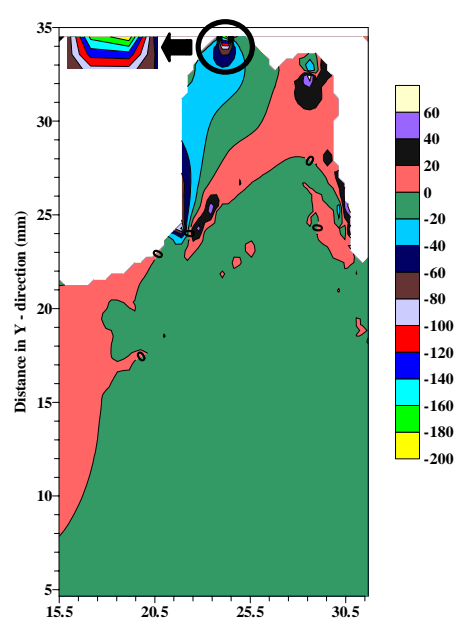

(B)Stress in X direction( $\mathrm{MPa})$

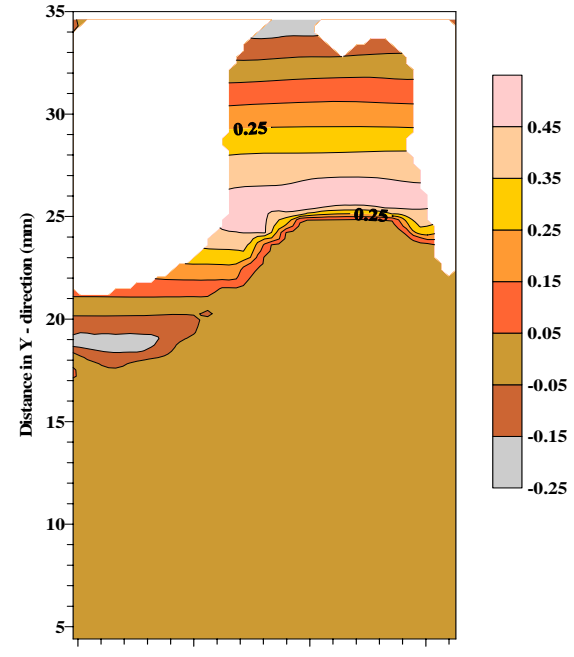

(C)Deflection in $\mathrm{X}$ direction $(\mathrm{mm})$

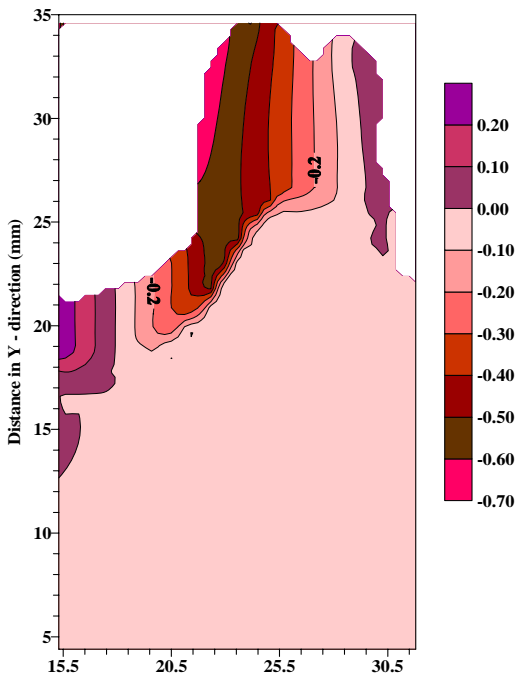

(D) Deflection in Y Direction(mm)
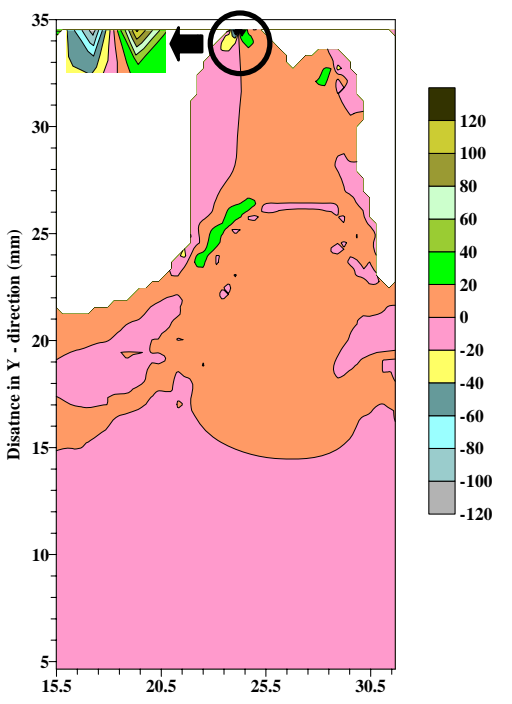

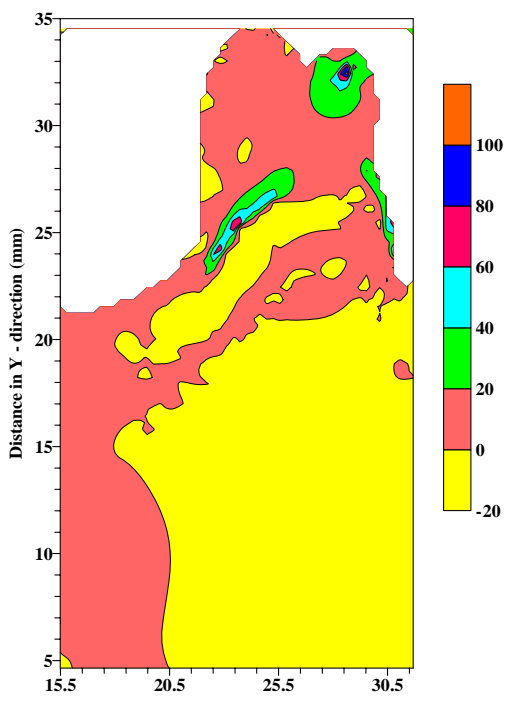

(F) Maximum principal stress (MPa)

Figure (4) Finite element analysis of acrylic denture to the underlying bone (Metal stock tray)

Deflection: The greater amount of deflection in the bucco - lingual direction was seen below the point of the force application at the buccal cusp of the second bicuspid tooth, and at the buccal vestibule ( -0.25 to $0.25,0$ to $0.7 \mathrm{~mm}$ ) in the $\mathrm{X}$ and $\mathrm{Y}$ axes respectively in the model that analyzed to the mucous membrane and (- 0.25 to $0.25,0$ to $0.7 \mathrm{~mm}$ ) in the $\mathrm{X}$ and $\mathrm{Y}$ axes respectively in the model that analyzed to the underlying bone.

The greater amount of deflection at the crest of the ridge was seen in the mucous membrane $(0.45 \mathrm{~mm})$ in the $\mathrm{X}$ axis, and in the mucous membrane at the crest of the ridge, and along the buccal vestibule in $\mathrm{Y}$ axis $(-0.6$ to $0.2 \mathrm{~mm})$ in the model that analyzed to the mucous membrane while in the model that analyzed to the underlying bone, the greater amount of deflection at the crest of the ridge was seen in the mucous membrane and the cortical bone $(0.45,0$ to $-0.1 \mathrm{~mm})$ in the $\mathrm{X}$ and $\mathrm{Y}$ axes respectively. The contour line of deflection values is shown in Figure (3 C and D) and Figure (4 C and D). 
Shear Stress: The maximum value of shear stress in the buccal direction was seen below the point of force application which was (-120 to $120 \mathrm{MPa})$ in the model that analyzed to the mucous membrane and the underlying bone. The maximum value of shear stress at the crest of the ridge was seen in the mucous membrane (20 to $20 \mathrm{MPa}$ ) in the model that analyzed to the mucous membrane and in the mucous membrane and at the beginning of the cortical bone (20 MPa) in the model that analyzed to the underlying bone. The contour line of shear stress is shown in Figure (3E and $4 \mathrm{E}$ ).

Maximum Principal Stress: The maximum principal stress value was seen below the lingual cusp of the second bicuspid tooth, in the mucous membrane at the crest of the ridge, and could be at the beginning of the buccal shelf (20 to 100 $\mathrm{MPa}$ ) in the model that analyzed to the mucous membrane and below the lingual cusp of the second bicuspid tooth, in the mucous membrane and in the cortical bone at the crest of the ridge (20 to $100 \mathrm{MPa})$ in the model that analyzed to the underlying bone. When the stress exceeds this value, crack and other complications will be expected to occur. The contour line of the maximum principal stress is shown in Figure (3 $\mathrm{F}$ and $4 \mathrm{~F})$.

\section{DISSCUSION}

The finite element method was used in this study to measure the denture stability and to evaluate a high pressure on the supporting structures. A two - dimensional finite element method to investigate the statics for the contour of the denture and the residual ridge was developed.

The maximum compressive stresses were observed below the point of force application at the buccal cusp of the second bicuspid tooth, and in the mucous membrane and cortical bone. These results are in agreement Vollmer et al. ${ }^{(15)}$, who reported that the forces applied to the masticatory system are manifested by the development of the internal stresses which are distributed in a coordinate with the direction of force application.

The maximum tensile stresses were observed in the mucous membrane. This results can be explained as to be due to the resiliency of this histological structure and

low value of modulus of elasticity of mucous membrane in relation to the acrylic resin and bone structure that is more dense and have high value of modulus of elasticity ${ }^{(16)}$.

The greater amount of deflection was seen below the point of force application specially in the buccal side of the model and this is related to the different topography of the models that produced from the tray ${ }^{(17)}$.

The maximum value of shear stress was seen below the point of force application and at the crest of the ridge in the mucous membrane and at the beginning of the cortical bone. This may be related to the friction between the acrylic denture and the underlying structure ${ }^{(10)}$.

The maximum principal stress value was seen in the mucous membrane, this results can be explained as to be duo to the resiliency and low modulus of elasticity of the mucous membrane ${ }^{(16)}$.

\section{CONCLUSIONS}

By using finite element analysis, the more stress concentration and deflection were found below the point of force application, in the mucous membrane at the crest of the ridge in the direction of the buccal side more than the lingual, at the beginning of the cortical bone and along the buccal vestibule.

\section{REFRENCES}

1. Breeding L, Dixon D, Moseley J. Custom impression trays: Part 1 - Mechanical Properties. J Prosthet Dent. 1994; 71: 31 34.

2. Johnson G, Craig R. Accuracy of addition silicone as a function of technique. J Prosthet Dent. 1986; 55: 197 - 203.

3. Yang H, Lang L, Felton D. Finite element stress analysis on the effect of splitting in fixed partial dentures. $J$ Prosthet Dent.1999; 81 (6): 721 - 728.

4. Kawasaki T, Takayama Y, Yamada T, Notani K. Relationship between the stress distribution and the shape of the alveolar residual ridge - three dimensional behavior of lower complete denture. J Oral Rehabil.2001; 28 (10): 950 - 957. 
5. Uto T. 3D finite element analysis in consideration of the slide on residual ridge and the rigidity of mandibular complete denture. Nippon Hotetsu Shika Gakkai Zasshi Japanese.2005; 49 (1): 36 - 45.

6. Jown B. Dental laboratory technology. Dentistry cn. 1968; 30: $15-18$.

7. Rees J, Huggett R, Harrison A. Finite element analysis of the stress - concentrating effect of fraenal notches in complete dentures. Int J Prosthod. 1990; 3: 238 240.

8. Sertgoz A, Guvener S. Finite element analysis of the effect of cantilever and implant length on stress distribution in an implant - supported fixed prosthesis. $J$ Prosthet Dent. 1996; 76: 165 - 169.

9. Hinton E, Owen DRJ. Finite element programming. Academic Press Ltd.,. 1977; Pp. 95 - 122.

10. Darbar U, Huggett R, Harrison A, Williams K. Finite element analysis of stress distribution at the tooth - denture base interface of acrylic resin teeth debonding from the denture base. J Prosthet Dent. 1995; 74: 591 - 594 .
11. Nakamura Y. Stress analysis of an overly denture and a magnetic attachment using finite element method. J Japan Prosthodontic Society. 1998; 42: 243.

12. Sato Y, Tsuga K, Abe Y, Akagawa Y. Finite element analysis of the effect of vertical curvature on half oval cast clasps. $J$ Oral Rehabil.1999; 26: 554 - 558.

13. Hong - So Y, Lisa A, Anthony M, David A. The effect of dowel design and load direction on dowel and core restoration. $J$ Prosthet Dent.2001; 85: 558 - 567.

14. Pegoretti A., Fambri L, Zappini G Bianchetti M. Finite element analysis of glass fiber reinforced composite endodntic post. J Biomaterial. 2002; 23: 2267 2282.

15. Vollmer D, Meyer U, Joos U, Vegh A, Piffko J. Experimental and finite element study of a human mandible. $J$ Eur Assoc. $2000 ; 28: 91-96$.

16. Hatim N. Volumetric changes in acrylic denture base material. M.Sc Thesis, College of Dentistry, University of Baghdad (1988). 